\title{
Resistant Starch Supplementation Influences Blood Lipid Concentrations and Glucose Control in Overweight Subjects
}

\author{
Ock Jin PARK ${ }^{1}$, Nam E KANG ${ }^{2}$, Moon Jeong CHANG ${ }^{3}$ and Woo Kyoung KIM ${ }^{4, *}$ \\ ${ }^{1}$ Deptartment of Food and Nutrition, Hannam University, 133 Ojeong-Dong, \\ Daedeok-Gu, Daejeon 306-791, Korea \\ ${ }^{2}$ Deptartment of Food and Nutrition, Seoul Health College, 212 Yangji-Dong, Sujung-Gu, \\ Sungnam 461-250, Korea \\ ${ }^{3}$ Department of Food and Life Science, 861-1 Chungnung-Dong, Songbuk-Gu, \\ Kookmin University, Seoul 136-702, Korea \\ ${ }^{4}$ Deptartment of Food Science and Nutrition, Dankook University, \\ San 8, Hannam-Dong, Youngsan-Gu, Seoul 140-714, Korea
}

(Received March 24, 2003)

\begin{abstract}
Summary Resistant starch (RS) includes the sum of starch and degradation products of starch that resist small intestinal digestion and enter the colon. This study was planned to examine the effect of resistant starch on hypolipidemic actions, blood glucose, insulin levels and humoral immune responses in healthy overweight subjects. Healthy overweight subjects (over $120 \%$ of their ideal body weights) were fed either $24 \mathrm{~g} / \mathrm{d}$ of resistant corn starch (RS) or regular corn starch (CS) for $21 \mathrm{~d}$ with their regular meals. Although this doubleblind feeding regiment resulted in no significant changes in their weights or other physical parameters for the relatively acute period of intakes, there were significant lowering effects of serum total cholesterol $(p<0.05)$ and serum LDL-cholesterol $(p<0.05)$ in subjects supplemented RS. Compared with the control starch group, the RS supplementation also reduced the mean fasting serum glucose concentrations $(p<0.05)$. Resistant starch supplement resulted in the increase in serum immunoglobulin G ( $\operatorname{IgG}$ ) concentrations. Serum insulin and complement $3\left(\mathrm{C}_{3}\right)$ were unaffected. Tested resistant starch supplementation was reported to be palatable with minimal bowel discomfort. These results suggest that RS supplementation improves the blood lipid profile and controls the blood glucose levels in healthy overweight subjects without bowel discomfort. Therefore, RS has a potential to be used as one of the promising food ingredients for reducing risk factors involved in the development of atherosclerosis and type 2 diabetes in overweight individuals. However, in order to prove RS as a novel therapeutic agent of cardiovascular diseases and diabetes, controlled trials with larger sample sizes and longer duration are warranted.
\end{abstract}

Key Words overweight subjects, resistant starch, blood lipid concentrations, glucose control

The past several years there has been continued interest in physiological effects of resistant starch, since it might be an attractive source of non-caloric food with a more palatable character than insoluble dietary fiber. The European PLAIR Concerted Action on Resistant Starch (EURESTA) has defined resistant starch (RS) as the sum of starch and products of starch hydrolysis not absorbed in the small intestine of healthy individuals (1, 2). Even though the importance of resistant starch to human health problems such as obesity, diabetes, atherosclerosis, and cancer has not been clearly elucidated, its hypolipidemic (3-7) and occasional prebiotic effects $(8-11)$ were noticed. It is generally accepted that RS replaced for digestible starch in the diet can lower serum cholesterol concentrations in normal or hypercholesterolemic conditions in animals (3-7). However,

${ }^{*}$ To whom correspondence should be addressed.

E-mail: wkkim@dankook.ac.kr in humans, these findings are not yet fully supported. For example, the cholesterol lowering effect has not been found with normolipidemic subjects (12). Also, postprandial cholesterol lowering effect was not observed with RS supplementation in healthy adults, even though there was a decrease in postprandial triacylglycerol concentration (13).

It has been proposed that the cholesterol-lowering effect observed in animal models is attributed to the increased production of short-chain fatty acids (SCFA) in the large intestine. In human studies, a general rise in SCFA was often examined $(9,10)$, however, there is no conclusive evidence that this is related to blood lipid performance. In fact, one study didn't find any significant correlation between fecal SCFA and blood lipid concentrations (14).

Generally a type of carbohydrate would alter glycemic responses in relation to the nature of the carbohydrate, food processing, availability to $\alpha$-amylase, gastric emp- 
tying time, and gut hormone profiles (15-17). In the small intestine, RS may be slowly absorbed and associated with an increased malabsorption of starch which may lead to decreased postprandial glucose and insulin responses (18). The previous studies on the relationship between the amount of available starch and blood glucose response has shown a general inverse relationship between blood glucose response and indigestible starch (18-21). However, at least two other studies reported that glycemic control was not affected with RS in their human subjects $(14,22)$.

The principle purpose of the present study was to investigate the effect of resistant starch on blood lipid concentrations, and glucose and insulin responses in overweight subjects. The humoral immune parameters (IgG and $\mathrm{C}_{3}$ ) were also observed in order to examine the effects of RS on immunity, which is often found to be reduced in overnutrition and obesity (23).

\section{MATERIALS AND METHODS}

Overweight or obese subjects (female; mean age $43.1 \pm 10.4$, range 26 to 57 ) were recruited from Seoul. The overweight and obese subjects were classified as over $120 \%$ of their ideal body weights. The participants had no serious medical complications other than a weight problem, are neither excessive drinkers nor under any form of medication. Participants underwent a physical examination, and then their blood was taken after an overnight $10-12 \mathrm{~h}$ fast. They received freezedried natural food, liquefied, once a day for $21 \mathrm{~d}$. After $21 \mathrm{~d}$, the blood sampling procedure was repeated. They were advised to follow similar dietary patterns and daily activities as before the study. All subjects signed a written informed consent agreement to participate in the study. The ethical committee of Dankook University, Seoul, Korea, approved all procedures of this research.

The subjects were asked to complete a questionnaire on dietary behaviors, medical history and lifestyle. Height was measured to the nearest $0.5 \mathrm{~cm}$ with a conventional measuring device and weight was measured to the nearest $0.1 \mathrm{~kg}$ with a digital metric scale while the subjects were lightly clothed and shoeless. Ideal body weight was calculated by the Broca method [(height $(\mathrm{cm})-100) \times 0.9]$. Body mass index $(\mathrm{BMI})$ was computed by weight/height ${ }^{2}\left(\mathrm{~kg} / \mathrm{m}^{2}\right)$. In all subjects, subcutaneous skinfold thickness was measured three times using a skinfold caliper at the triceps and the average values were obtained. The arm, waist and hip circumferences were measured according to Lapidus and Bengtsson (24). Fat masses were estimated with the method of bio-electrical impedance analysis using GIF891 model (Gilwoo Trading Co., Korea). Systolic and diastolic blood pressures were measured to the nearest $2 \mathrm{mmHg}$ after the subjects were rested for $10 \mathrm{~min}$. Daily nutrient intake data was calculated from $3 \mathrm{~d}, 24 \mathrm{~h}$ recall consumption using the Computer-Aided Nutritional Analysis (CAN) program (Korean Nutrition Society).

The study consisted of a double-blind design with 13 control subjects and 12 experimental subjects. The con-
Table 1. Composition of regular starch supplement (CS) and resistant starch supplement (RS).

$(100 \mathrm{~g})$

\begin{tabular}{lcc}
\hline & CS & RS \\
\hline Starch $(\mathrm{g})$ & & \\
Regular & 81 & 21 \\
Resistant & - & 60 \\
Protein & 4.9 & 4.9 \\
Fat $(\mathrm{g})$ & 2.9 & 2.9 \\
\hline
\end{tabular}

trol group (CS) and experimental group (RS) were divided randomly and the control group received a regular corn starch supplement while the experimental group received resistant corn starch. Both supplements contained $60 \%$ starch powder with minor ingredients of dried whole grain, vegetables, mushrooms and seaweed. The composition of resistant starch supplement and regular starch supplement starch is in Table 1. The subjects were asked to take $40 \mathrm{~g}$ of starch supplements in $250 \mathrm{~mL}$ of water each day between 3-5 p.m. for $21 \mathrm{~d}$.

For the preparation of RS, corn starch (amylose contents; $27 \%$ by manufacturer, Daesang Co., Korea) was dissolved in $4 \times$ volume of boiling water, boiled for 10 min while stirring, removed from heat and simmered for $5 \mathrm{~min}$ while stirring. Then the suspension was cooled down to $30^{\circ} \mathrm{C}$, vacuum-sealed in a retort pouch and autoclaved at $121^{\circ} \mathrm{C}$ under 15 psi for $1 \mathrm{~h}$, and then stored at $4^{\circ} \mathrm{C}$ for $24 \mathrm{~h}$. After four cycles of autoclaving and cooling, RS contents were estimated to be $24 \%$ as determined by Total Dietary Fiber determination kit (TDF-100A, Sigma Co., USA). To remove remaining starch not retrograded, the preparation was then dissolved in 10 times volume of water and allowed to stand for $24 \mathrm{~h}$, and hydrolyzed with $15 \mathrm{~g} / \mathrm{kg} \alpha$-amylase (total unit; 8,000 U, from Bacillus globigii, Junsei Co., Japan) at $90^{\circ} \mathrm{C}$. The sediments were then washed and hot-air dried at $60^{\circ} \mathrm{C}$. This enzymatic hydrolytic process removed the unchanged starch and the resulting RS was considered to be pure.

For the serum collection, the subjects were asked to fast overnight and then blood was withdrawn, and serum was separated from cells by centrifugation. Serum samples were then stored at $-70^{\circ} \mathrm{C}$ until analysis.

Serum total cholesterol and triacylglycerol were measured enzymatically using a commercial kit (Asan Pharmaceutical Co., Seoul, Korea). HDL-cholesterol was measured enzymatically after precipitation of apolipoprotein B containing lipoproteins with dextran sulfate according to the method of Sjoblom and Eklund (25). LDL-cholesterol was calculated according to the Friedewald formula (26). Serum glucose was measured using a commercial kit (Asan Pharmaceutical Co.). Immunoreactive insulin was determined by radioimmunoassay with coat-A-count insuline (DPC, USA). Serum immunoglobulin $\mathrm{G}(\mathrm{IgG})$ and $\mathrm{C}_{3}$ were measured according to the method of rate nephelometry (27). 
Table 2. Anthropometric data of subjects.

\begin{tabular}{|c|c|c|c|c|}
\hline \multirow{2}{*}{ Variable } & \multicolumn{2}{|c|}{$\operatorname{CS}(n=13)$} & \multicolumn{2}{|c|}{$\operatorname{RS}(n=12)$} \\
\hline & Baseline & After & Baseline & After \\
\hline Age $(y)$ & $43.6 \pm 2.8$ & & $42.3 \pm 3.1$ & \\
\hline Weight (kg) & $68.6 \pm 1.6$ & $68.8 \pm 1.6$ & $65.0 \pm 2.0$ & $64.8 \pm 2.2$ \\
\hline Height $(\mathrm{cm})$ & $156.7 \pm 1.4$ & $156.7 \pm 1.4$ & $156.3 \pm 1.5$ & $156.3 \pm 1.5$ \\
\hline $\mathrm{ST}(\mathrm{mm})$ & $27.8 \pm 1.5$ & $27.1 \pm 1.6$ & $31.2 \pm 1.2$ & $30.5 \pm 1.3$ \\
\hline $\mathrm{AC}(\mathrm{cm})$ & $31.3 \pm 0.5^{*}$ & $32.4 \pm 0.6^{*+}$ & $29.4 \pm 0.5$ & $29.8 \pm 0.5$ \\
\hline $\mathrm{HC}(\mathrm{cm})$ & $104.1 \pm 0.8$ & $103.5 \pm 0.9^{*}$ & $99.1 \pm 2.6$ & $98.3 \pm 1.8$ \\
\hline $\mathrm{WC}(\mathrm{cm})$ & $88.7 \pm 1.7^{*}$ & $87.9 \pm 1.7^{*}$ & $82.7 \pm 1.9$ & $81.7 \pm 1.8$ \\
\hline PBF $(\%)$ & $35.5 \pm 1.0$ & $35.8 \pm 1.0$ & $35.5 \pm 1.1$ & $34.4 \pm 1.6$ \\
\hline Obesity (\%) & $34.7 \pm 2.7$ & $35.2 \pm 2.9$ & $29.5 \pm 3.3$ & $29.5 \pm 3.3$ \\
\hline $\mathrm{BMI}\left(\mathrm{kg} / \mathrm{m}^{2}\right)$ & $27.9 \pm 0.5$ & $28.0 \pm 0.5$ & $26.6 \pm 0.7$ & $26.7 \pm 0.7$ \\
\hline SBP (mmHg) & $125.5 \pm 5.0$ & $135.2 \pm 4.7$ & $122.1 \pm 2.2$ & $116.8 \pm 8.9$ \\
\hline $\mathrm{DBP}(\mathrm{mmHg})$ & $74.7 \pm 2.9$ & $77.0 \pm 3.8$ & $74.8 \pm 1.7$ & $76.9 \pm 1.8$ \\
\hline
\end{tabular}

Data are shown as mean \pm SE.

ST: skinfold thickness, AC: arm circumference, HC: hip circumference, WC: waist circumference, PBF: percent body fat, SBP: systolic blood pressure, DBP: diastolic blood pressure.

* Significantly different by Student's $t$-test between control and experimental groups at $p<0.05$.

+ Significantly different between baseline and after treatment by paired $t$-test at $p<0.05$.

Table 3. The nutrition status of subjects at the baseline,

\begin{tabular}{lcc}
\hline \multicolumn{1}{c}{ Variable } & CS $(n=13)$ & RS $(n=12)$ \\
\hline Energy $(\mathrm{kcal})$ & $1,906.7 \pm 164.1$ & $1,740.7 \pm 113.7$ \\
Protein $(\mathrm{g})$ & $73.7 \pm 9.4$ & $65.6 \pm 6.7$ \\
Fat $(\mathrm{g})$ & $41.0 \pm 5.5$ & $39.3 \pm 4.9$ \\
Carbohydrate $(\mathrm{g})$ & $299.1 \pm 25.6$ & $269.7 \pm 17.1$ \\
Ca $(\mathrm{mg})$ & $644.9 \pm 89.8$ & $769.6 \pm 52.7$ \\
$\mathrm{P}(\mathrm{mg})$ & $1,022.2 \pm 102.0$ & $1,016.7 \pm 77.9$ \\
Fe $(\mathrm{mg})$ & $15.7 \pm 1.8$ & $14.5 \pm 1.9$ \\
Na $(\mathrm{mg})$ & $8,450.6 \pm 2.529 .6$ & $9,385.7 \pm 1.524 .0$ \\
Zn $(\mathrm{mg})$ & $5.2 \pm 0.6$ & $5.1 \pm 0.6$ \\
Vitamin A (RE) & $781.3 \pm 95.7$ & $564.7 \pm 126.7$ \\
Vitamin E (mg) & $10.3 \pm 2.5$ & $9.5 \pm 1.9$ \\
Thiamin $(\mathrm{mg})$ & $1.1 \pm 0.1$ & $1.2 \pm 0.1$ \\
Riboflavin $(\mathrm{mg})$ & $1.3 \pm 0.1$ & $1.4 \pm 1.1$ \\
Niacin $(\mathrm{mg})$ & $17.9 \pm 2.9$ & $15.0 \pm 1.7$ \\
Folate $(\mu \mathrm{g})$ & $84.1 \pm 20.4$ & $67.0 \pm 12.7$ \\
Vitamin C (mg) & $158.9 \pm 27.2$ & $145.5 \pm 30.7$ \\
Fiber $(\mathrm{g})$ & $9.1 \pm 1.3$ & $9.0 \pm 1.7$ \\
&
\end{tabular}

Data are shown as mean \pm SE.

Subjects were asked to report on a daily basis defecation frequency, duration and the degree of bowel discomfort. The symptoms of nausea, distention and flatulence intensity were comprised of $0-10$ scale $(0$ representing 'absent' and 10 'severe').

Statistical analysis was performed using the Statistical Analysis System (SAS, v6.0). Data were expressed as the mean with standard error, and statistically significant differences of the means between two groups were evaluated by Student's $t$-test and differences of the means between baseline and after supplementation were by paired $t$-test.

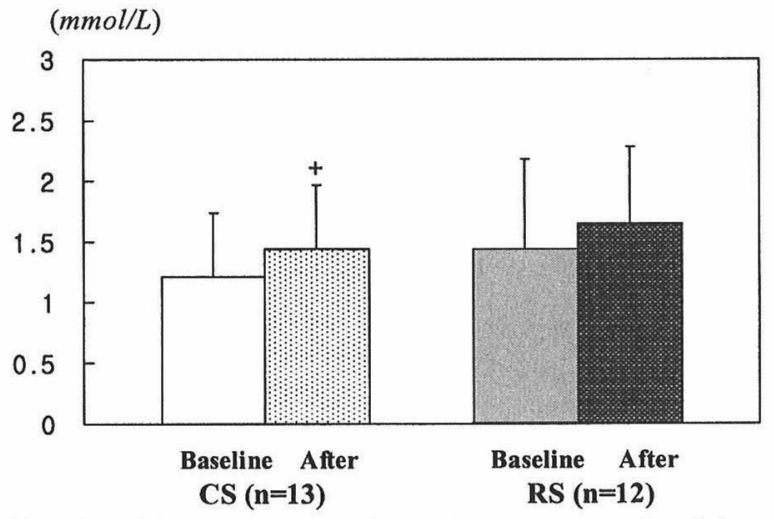

Fig. 1. Effects of resistant starch on serum triacylglycerol in overweight subjects. Data are shown as mean \pm SE. + : significantly different by paired $t$-test between baseline and after treatment at $p<0.05$.

\section{RESULTS}

Anthropometric characteristics of the subjects are presented in Table 2. There were no significant differences in major characteristics between the two experimental groups. There was no change in body weights after $21 \mathrm{~d}$ of the study period.

No significant differences were found in nutrient intakes before supplementing $24 \mathrm{~g}$ of regular corn starch or resistant corn starch containing powder with a regular diet for $21 \mathrm{~d}$ (Table 3 ).

Figures 1-4 represent the results of the effect of supplementing resistant starch on serum triacylglycerols, total cholesterol, LDL-cholesterol and HDL-cholesterol at the baseline and after supplementation. After $21 \mathrm{~d}$ of supplementation, serum triacylglycerol concentrations of RS group remained unchanged, whereas CS group showed a significant increase. Supplementing RS decreased serum total cholesterol $(p<0.05)$, and LDL-cho- 


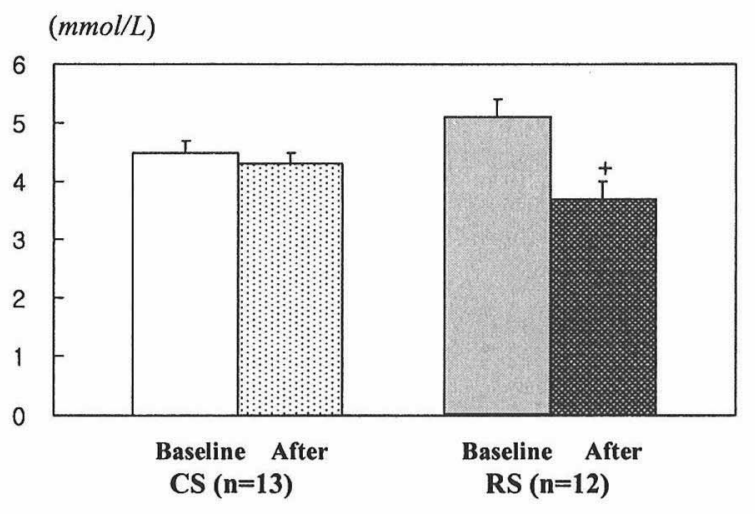

Fig. 2. Effects of resistant starch on serum total cholesterol in overweight subjects. Data are shown as mean \pm SE. + : significantly different by paired $t$-test between baseline and after supplementation at $p<0.05$.

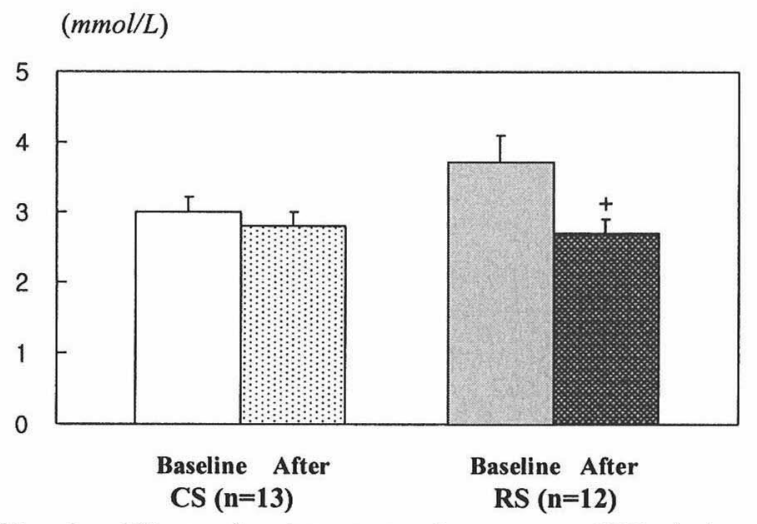

Fig. 3. Effects of resistant starch on serum LDL-cholesterol in overweight subjects. Data are shown as mean \pm SE. + : significantly different by paired $t$-test between baseline and after supplementation at $p<0.05$.

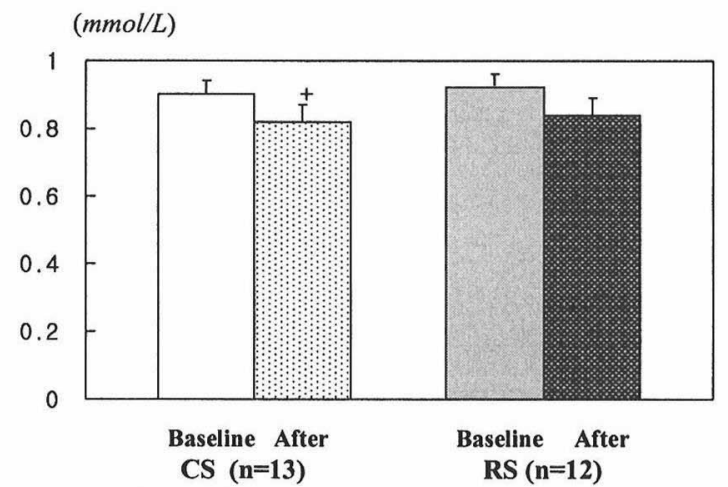

Fig. 4. Effects of resistant starch on serum HDL-cholesterol in overweight subjects. Data are shown as mean \pm SE. + : significantly different by paired $t$-test between baseline and after supplementation at $p<0.05$.

lesterol $(p<0.05)$ concentrations in overweight subjects. No such decrease was found with feeding control starch supplementation. HDL-cholesterol was unaffected.

Fasting serum glucose levels were significantly decreased after supplementation (Fig. 5). However, there was no significant influence of resistant starch on serum insulin concentrations (Fig. 6).

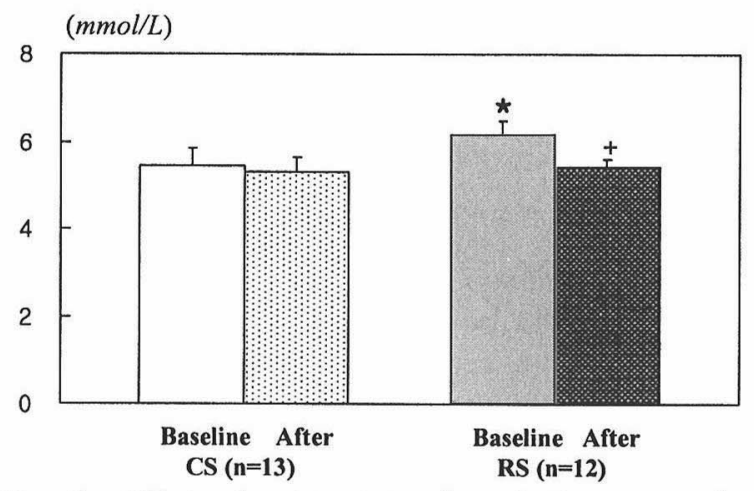

Fig. 5. Effects of resistant starch on fasting serum glucose in overweight subjects. Data are shown as mean \pm SE. *: significantly different by Student's $t$-test between CS and RS at $\alpha=0.05$. +: significantly different by paired $t$-test between baseline and after supplementation $p<0.05$.

\section{(uIU/ml)}

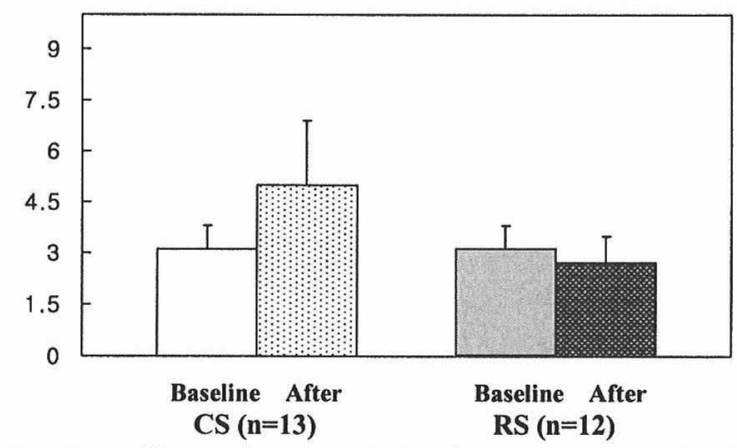

Fig. 6. Effects of resistant starch on serum insulin in overweight subjects. Data are shown as mean \pm SE.

RS supplementation appeared to stimulate the response of serum IgG. No significant resistant starch supplementation was found in $\mathrm{C}_{3}$ concentrations (Table $4)$.

No significant effects were found with regard to defecation frequency, defecation time or the degree of bowel complaint at the baseline and after treatment in both of the study groups (Table 5).

\section{DISCUSSION}

The purpose of the present study was to examine the effects of the consumption of resistant starch in overweight subjects using various parameters related to hypercholesterolemia and glucose control. One of the significant effects of resistant starch is the lowering of serum total cholesterol and LDL-cholesterol concentrations in this study. In human study, dietary high-amylose cornstarch compared to low-amylose starch decreased blood cholesterol concentrations by $30-36 \%$ (28). The range of cholesterol lowering was from $8 \%$ to $23 \%$ in subsequent studies (3-6). Triacylglycerol concentration changes were more variable than cholesterol with the range of $0-42 \%(3-5)$. The reason why there is no triacylglycerol lowering effect of RS is not clear from this study. But in other studies with hyperlipidemic or normolipidemic subjects, raw or retrograded RS did not 
Table 4. Effects of resistant starch on the levels of $\operatorname{IgG}$ and $C_{3}$ in serum in overweight subjects.

$(\mathrm{mg} / \mathrm{dL})$

\begin{tabular}{lccccc}
\hline & \multicolumn{2}{c}{$\operatorname{CS}(n=13)$} & & \multicolumn{2}{c}{$\mathrm{RS}(n=12)$} \\
\cline { 2 - 3 } \cline { 5 - 6 } & Baseline & After & & Baseline & After \\
\hline IgG & $1,222.2 \pm 40.8$ & $1,209.6 \pm 48.8$ & & $1,079.8 \pm 61.4$ & $1,149.8 \pm 57.3^{+}$ \\
$C_{3}$ & $134.7 \pm 1.4$ & $118.8 \pm 4.8^{+}$ & & $113.0 \pm 116.2$ & $116.2 \pm 6.68$ \\
\hline
\end{tabular}

Data are shown as mean \pm SE.

${ }^{+}$Significantly different between baseline and after treatment by paired $t$-test at $p<0.05$.

Table 5. Effects of resistant starch on defecation frequency, time, and bowel complaint in overweight subjects.

\begin{tabular}{lccccc}
\hline & \multicolumn{2}{c}{ CS $(n=13)$} & & \multicolumn{2}{c}{$\operatorname{RS}(n=12)$} \\
\cline { 2 - 5 } & Baseline & After & & Baseline & After \\
\hline Defecation frequency (number/d) & $2.3 \pm 1.0$ & $2.1 \pm 0.8$ & & $2.0 \pm 0.8$ & $2.0 \pm 1.0$ \\
Defecation time (min) & $6.7 \pm 7.8$ & $6.3 \pm 5.6$ & & $6.8 \pm 7.2$ & $6.6 \pm 7.6$ \\
Degree of bowel complaint* & $3.3 \pm 0.8$ & $2.8 \pm 0.9$ & & $2.8 \pm 0.8$ & $2.9 \pm 1.0$ \\
\hline
\end{tabular}

Data are shown as mean \pm SE.

* The score of nausea, distention and flatulence intensity comprised of a 0-10 scale ( 0 representing 'absent' and 10 'severe').

lower serum lipid concentrations $(12,14,29)$.

Part of the starch, after heating and subsequent cooling, can be converted into an indigestible fraction called resistant starch. The hydrothermic treatment followed by keeping disorganized starch macromolecules at a low temperature $\left(4^{\circ} \mathrm{C}\right)$ can be repeated to increase RS transformation. This evolution of starch is defined as highly resistant starch in recrystallized form of amylose and amylopectin (30). Several investigators have proposed RS as a new category of dietary fiber possessing some metabolic functions against abnormality caused by over supply of energy or fat (31). Since RS remains mostly undigested until it is partially fermented in the colon, the metabolism of RS appears to occur $5-7 \mathrm{~h}$ after consumption in contrast to normally cooked starch which is digested almost immediately (32). It has been suggested that retrograded starch may lower the serum cholesterol concentration by several mechanisms, including an increase in fecal bile acid excretion (7). However, not every type of RS can bind bile acids. RS, in the form of resistant starch granules, (in the case of raw potato starch) does not seem to bind to bile acids (7). Besides, the systemic effect of propionate on cholesterol synthesis can be considered as one of the mechanisms of cholesterol lowering effect of RS. It has been proposed that soluble plant fiber lowers plasma cholesterol concentrations by inhibition of hepatic cholesterol synthesis via propionate formed through large-bowel fermentation (33). And SCFA has been shown to suppress cholesterol synthesis in the liver and intestine of rats (34). However, previously it has been argued that in vivo production of propionate by diet alone is not high enough to decrease the activity of hydroxymethylglutaryl-CoA reductase (35). Even though the exact mechanism of cholesterol-lowering effect of RS is unclear at present, RS appears to be an attractive source of carbohydrate reducing atherogenic potentials without altering its organoleptic properties $(5,36)$. Carbohydrates that reach the large intestine provide potential energy to colonic microorganisms. Many in vivo studies have shown that RS may be readily fermented by colonic microflora, but differences in fermentability were found (29). It has been claimed that starch is completely fermented by gut bacteria (12). Further study is needed to clarify the exact colonic process followed by the ingestion of different types of RS.

Fasting glucose was significantly higher with control starch supplementation compared to the resistant starch, whereas fasting insulin was unchanged by the two kinds of starch. The differences in fasting glucose response can be attributed from the different energy contents of the supplements. The subjects consumed approximately $24 \mathrm{~g}$ starch per day in addition to their regular diet. Since body weight alteration was not found with both the control group and the experimental group after $21 \mathrm{~d}$ of supplementation, the subjects may have been compensated through the reduced energy intake of their regular diet, especially for the control group.

The reason for the variations in glycemic control responses that were observed with RS feeding human studies is not clear. The differences in nature of RS, study subjects as well as feeding regiments may be the contributing factors. In fact, the differences in RS have been suggested to play a role in glycemic response (12). Wolf et al. (22) have found no significant glucose lowering action with RS from corn, whereas Wakabayashi et al. (21) have noticed a beneficial glycemic response with RS from potato.

In relation to glucose response, serum insulin concentrations were measured. There were no significant differences in serum insulin concentrations. Some studies have observed the improvement of insulin response along with glucose response by feeding RS $(18,19,21)$. 
A slight modulation of humoral immunity as measured by IgG levels was noticed.

The habitual pattern of defecation of the study subjects was not changed with the consumption of RS. No report of physiological bowel discomfort was noted by feeding RS in this study.

In summary, it has been shown that resistant starch supplementation at the level of $24 \mathrm{~g} / \mathrm{d}$ with their regular diet could lower serum cholesterol and glucose concentrations in overweight subjects. These physiological actions along with favorable palatability without bowel discomfort render resistant starch as an attractive food ingredient for controlling the risk factors of atherosclerosis and diabetes development.

\section{Acknowledgments}

This study was supported by a grant of the Korea Health 21 R\&D Project, Ministry of Health \& Welfare, Republic of Korea (00-PJ1-PG4-PT04-0005).

\section{REFERENCES}

1) Euresta (European Flair Concerted Action on Resistant Starch). 1993. Newsletter IV. Department of Human Nutrition, Wageningen Agriculture University.

2) Wisker E. 1997. Physiological effects of resistant starch-Part 1: Definition, intake with food, and influence on glucose, insulin and lipid plasma levels. Ernnahrungs-umschau 47: 10-15.

3) de Deckere EAM, Kloots WJ, van Amelsvoort JMM. 1993. Resistant starch decreases serum total cholesterol and triacylglycerol concentrations and fat accretion in the rat. Br J Nutr 73: 74-76.

4) de Deckere EAM, Kloots WJ, van Amelsvoort JMM. 1995. Both raw and retrograded starch decrease serum triacylglycerol concentration and fat accretion in the rat. Br J Nutr 72: 287-298.

5) Younes H, Levrat MA, Demigne C, Remesy C. 1995. Resistant starch is more effective than cholestyramine as a lipid-lowering agent in the rat. Lipids 30: 847-853.

6) Vanhoof K, de Schrijver R. 1997. Consumption of enzyme-resistant starch and cholesterol metabolism in normo- and hypercholesterolemic rats. Nutr Res 17: 1331-1340.

7) Levrat MA, Moundras C, Younes H, Morand C, Demigne C, Remesy C. 1996. Effectiveness of resistant starch, compared to guar gum, in depressing plasma cholesterol and enhancing fecal steroid excretion. Lipids $\mathbf{3 1}$ : 1069-1075.

8) Haralampu SG. 2000. Resistant starch-a review of the physical properties and biological impact of RS3. Carb Polymers 41: 285-292.

9) van Munster IP, Tangerman A, Nagengast FM. 1994. Effect of resistant starch on colonic fermentation, bile acid metabolism, and mucosal proliferation. Dig Dis Sci 39: 834-842.

10) Phillips J, Muir JG, Birkett A, Lu ZX, Jones GP, O'Dea K, Young GP. 1995. Effect of resistant starch on fecal bulk and fermentation-dependent events in humans. Am J Clin Nutr 62: 121-130.

11) Cheng HH, Lai MH. 2000. Fermentation of resistant rice starch produces propionate reducing serum and hepatic cholesterol in rats. J Nutr 130: 1991-1995.

12) Heijnen MA, van Amelsvoort JMM, Deurenberg P, Bey- nen AC. 1996. Neither raw nor retrograded resistant starch lowers fasting serum cholesterol concentrations in healthy normolipidemic subjects. Am J Clin Nutr 64: $312-318$.

13) Marchini JS, Faisant N, Champ M, Ranganathan S, Azoulay C, Kergueris MF, Piloquet H, Krempf M. 1998. Effects of an acute raw resistant potato starch supplement on postprandial glycemia, insulinemia, lipidemia in healthy adults. Nutr Res 18: 1135-1145.

14) Jenkens DJ, Vuksan V, Kendall CW, Wursch P, Jeffcoat R, Waring S, Mehling CC, Vidgen E, Augustin LS, Wong E. 1998. Physiological effects of resistant starches on fecal bulk, short chain fatty acids, blood lipids and glycemic index. J Am Coll Nutr 17: 609-616.

15) Tappy L, Wursch JP, Randin JP, Felber JP, Jequier E. 1986. Metabolic effect of precooked instant preparations of bean and potato in normal and diabetic subjects. Am J Clin Nutr 43: 30-36.

16) Jenkins DJ, Jenkins AL, Wolever TM, Collier GR, Roo AV, Thompson LV. 1987. Starchy foods and fiber reduced rate of digestion and improved carbohydrate metabolism. Scand J Gastroenterol 22: 132-141.

17) van Amerlsvoort JMM, Westrate JA. 1992. Amyloseamylopectin ratio in a meal affects postprandial variables in male volunteers. Am J Clin Nutr 55: 712-718.

18) Raben A, Tagliabue A, Christensen NJ, Madsen J, Holst JJ, Astrup A. 1994. Resistant starch: the effect on postprandial glycemia, hormonal response and satiety. Am J Clin Nutr 60: 544-551.

19) Reader A, Johnson ML, Hollander P, Franz M. 1997. Response of resistant starch in a food bar vs two commercially available bars in persons with type II diabetes mellitus. Diabetes 46: $254 \mathrm{~A}$.

20) Lilheberg HGM, Akerberg AKE, Bjorck IME. 1999. Effect of the glycemic index and content of indigestible carbohydrates of cereal-based breakfast meals on glucose tolerance at lunch in healthy subjects. Am J Clin Nutr 69: 647-655.

21) Wakabayashi S, Kishimoto Y, Nanbu S, Matsuoka A. 1999. Effects of indigestible dextrin on postprandial rise in blood glucose levels in man. J Jpn Assoc Dietary Fiber Res 3: 13-19.

22) Wolf BW, Wolever TMS, Bolognesi C, Zinker BA, Garleb KA. 2001. Glycemic response to a rapidly digested starch is not affected by the addition of an indigestible dextrin in humans. Nutr Res 21: 1099-1106.

23) Chandra RK. 2002. Nutrition and the immune system from birth to old age. Eur J Clin Nutr 56: 73S-76S.

24) Lapidus L, Bengtsson C. 1988. Regional obesity as a health hazard in women-a prospective study. Acta Med Scand S723: 5-59.

25) Sjoblom L, Eklund A. 1989. Determination of $\mathrm{HDL}_{2}$ cholesterol by precipitation with dextran sulfate and magnesium chloride: establishing optimal conditions for rat plasma. Lipids 24: 532-534.

26) Friedwald WT, Levy RI, Fredrickson DS. 1972. Estimation of the concentration of low density lipoprotein cholesterol in plasma, without use of the preparative ultracentrifugation. Clin Chem 18: 499-502.

27) Sternberg JC. 1977. A rate nephelometer for measuring specific proteins by immunoprecipitate reaction. Clin Chem 23: 1456-1464.

28) Behall KM, Scholfield DJ, Yuhaniak I, Canary J. 1989. Diets containing high amylose vs amylopectin starch: effects on metabolic variables in human subjects. Am J 
Clin Nutr 49: 337-344.

29) Noakes M, Clifton PM, Nestel PJ, LeLeu R, McLntosh G. 1996. Effect of high-amylose starch and oat bran on metabolic variable and bowel function in subjects with hypertriglyceridemia. Am J Clin Nutr 64: 944-951.

30) Pomeranz Y. 1992. Research and development regarding enzyme-resistant starch (RS) in the USA: a review. Eur J Clin Nutr 46: S63-S69.

31) Bornet F. 1993. Technological treatments of cereals. Discussions on the physiological properties of starch. Carb Polymers 21: 195-203.

32) Muir JG, Lu ZX, Young GP, Cameron SD, Collier GR, O'Dea K. 1995. Resistant starch in the diet increases breath hydrogen and serum acetate in human subjects. Am J Clin Nutr 61: 792-799.
33) Chen WJL, Anderson JW, Jennings D. 1984. Propionate may mediate the hypocholesterolemic effects of certain soluble plant fibers in cholesterol fed rats. Proc Soc Exp Biol Med 175: 215-218.

34) Hara H, Haga S, Aoyama Y, Kiriyama S. 1999. Shortchain fatty acids suppress cholesterol synthesis in rat liver and intestine. J Nutr 129: 942-948.

35) Bearlieu KE, McBurney MI. 1992. Changes in pig serum lipids, nutrient digestibility and sterol excretion during cecal infusion of propionate. J Nutr 122: 241-245.

36) Fernandez ML, Suheeta R, Vergara JM. 2000. Resistant starch and cholestyramine have distinct effects on hepatic cholesterol metabolism in guinea pigs fed a hypercholesterolemic diet. Nutr Res 20: 837-849. 